\title{
Successful Remission of Extensive Liver Metastases in a Breast Cancer Patient with Acute Liver Failure Using a Combined Chemotherapy Regimen with Mitomycin, Folinate, and 5-Fluorouracil (Mi/Fo/FU)
}

\author{
Natalija Stoiber ${ }^{a, b} \quad$ Nik Hauser $^{\mathrm{a}} \quad$ Bernhard Stoiber $^{\mathrm{c}, \mathrm{b}} \quad$ Michael K. Hohl $^{\mathrm{a}}$ \\ Christof Sohn ${ }^{\mathrm{b}}$ Michael H.R. Eichbaum ${ }^{\mathrm{b}}$

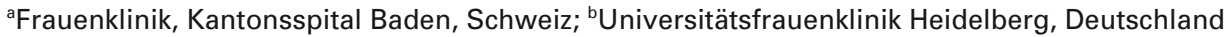 \\ 'Departement Frauenheilkunde, Universitätsspital Zürich, Schweiz
}

Key Words

Mi/Fo/FU · Breast cancer · Liver failure · Jaundice

\section{Summary}

Background: Liver failure due to disseminated hepatic secondaries represents a therapeutic dilemma in patients with metastatic breast cancer (MBC). Reduced liver function and non-assessable toxicity are limiting factors in the selection of chemotherapeutic agents. Currently, there is no standard treatment after failure of anthracycline- and taxanebased first-line therapies, although there is a variety of well evaluated drugs such as capecitabine. Case Report: We report on a 45-year-old breast cancer patient with disseminated hepatic metastases. She presented in markedly poor condition, showing substantial ascites and extensive jaundice. Blood chemistry analysis showed increased serum levels of liver enzymes (aspartate aminotransferase $271 \mathrm{U} / \mathrm{l}$, alanine transaminase $101 \mathrm{U} / \mathrm{l})$, bilirubin $(7.9 \mathrm{mg} / \mathrm{dl})$, and CA 15-3 (1,459 U/I). We induced a palliative chemotherapy with mitomycin, folinate, and 5-fluorouracil (Mi/Fo/FU). The patient improved impressively after the first cycle of systemic therapy. Liver enzymes stabilized continuously, CA 15-3 returned to normal. The patient was discharged 2 weeks after the treatment start. Chemotherapy was well tolerated under dose escalation, no grade $3 / 4$ toxicity was observed. The progression-free interval was 5 months. Conclusions: A combination therapy with $\mathrm{Mi} / \mathrm{Fo} / \mathrm{FU}$ appears to be a reasonable and tolerable alternative salvage strategy for patients with liver failure due to hepatic breast cancer metastases. $\overline{\text { Schlüsselwörter }}$

Mi/Fo/FU · Mammakarzinom · Leberversagen · Ikterus

\section{Zusammenfassung}

Hintergrund: Eine fulminante Lebermetastasierung mit drohendem Organversagen stellt eine therapeutische Herausforderung in der Behandlung von Patientinnen mit metastasiertem Mammakarzinom dar. Die eingeschränkte Leberfunktion und nicht abschätzbare Toxizitäten sind limitierende Faktoren für die Wahl geeigneter Chemotherapeutika. Trotz guter Evaluation einer Reihe von Chemotherapeutika wie z.B. Capecitabine gibt es aktuell keine Standardbehandlung nach Versagen von anthrazyklin- und taxanbasierten Therapien in der Erstlinien-Situation. Fallbericht: Eine 45-jährige Mammakarzinompatientin mit disseminierten hepatischen Metastasen stellte sich in stark reduziertem Allgemeinzustand mit massivem Aszites und ausgeprägtem Ikterus vor. Zum Zeitpunkt der Aufnahme waren die Serumwerte der Transaminasen (Glutamat-Oxalacetat-Transaminase $271 \mathrm{U} / \mathrm{l}$, Glutamat-Pyruvat-Transaminase $101 \mathrm{U} / \mathrm{l})$, des Gesamtbillirubins $(7,9 \mathrm{mg} / \mathrm{dl})$ und des CA 15-3 (1.459 U/l) deutlich erhöht. Wir initiierten eine palliative Kombinationschemotherapie mit Mitomycin, Folinat und 5-Fluorouracil (Mi/Fo/FU). Bei deutlichem klinischen Ansprechen bereits nach dem ersten Therapiezyklus konnten wir die Patientin 2 Wochen nach Beginn der Chemotherapie aus der stationären Behandlung entlassen. Die Therapie war unter adaptierter Dosiseskalation gut verträglich. Es wurden keine Grad-3/4Toxizitäten während einer Behandlungsdauer von 5 Therapiezyklen beobachtet. Eine Krankheitsstabilisierung für 5 Monate konnte erreicht werden. Schlussfolgerungen: Die vorgestellte Kasuistik verdeutlicht, dass eine Mi/Fo/FU-Kombinationschemotherapie eine gut durchführbare und effektive Therapieoption für Patientinnen mit ausgeprägter hepatischer Dysfunktion durch disseminierte Lebermetastasen eines Mammakarzinoms darstellt.

\begin{tabular}{ll}
\hline KARGER & $\oplus$ 2010 S. Karger GmbH, Freiburg \\
Fax +497614520714 & Accessible online at: \\
Information@Karger.de & www.karger.com/onk \\
www.karger.com &
\end{tabular}




\section{Introduction}

Jaundice due to disseminated hepatic metastases often represents a complex therapeutic dilemma in the treatment of patients with metastatic breast cancer (MBC). The associated hepatic dysfunction frequently limits the selection of therapeutic agents due to unpredictable toxicity in the setting of altered hepatic clearance. At the same time, the presence of liver metastases is in itself considered as a poor prognostic factor for patients with MBC. Generally, these patients have been shown to be less responsive to chemotherapy when compared to patients without hepatic involvement. The median survival shows a range of 1-20 months after initial diagnosis of liver metastases [1-3]. The principal aims of palliative treatment in this setting are disease control, relief of symptoms, and improvement or maintenance of quality of life. The two most active classes of cytotoxic agents available for the treatment of breast cancer are anthracyclines and taxanes. Taxanes are primarily eliminated via the bile system and feces. Therefore, the use of taxanes in patients with elevated serum bilirubin or pathologic liver function tests is limited. Anthracyclines are predominantly metabolized by the liver. Impaired liver function delays the excretion and increases the accumulation of the drug in tissue and plasma. For doxorubicin, dose reductions are generally necessary depending on the bilirubin levels. Bilirubin levels higher than $5.0 \mathrm{mg} / \mathrm{dl}$ are a contraindication for the use of doxorubicin. After the diagnosis of abnormal liver function, all chemotherapeutic agents commonly used for the treatment of MBC have to be administered with caution. Fatal cholestatic liver failure associated with a gemcitabine therapy in MBC has been reported [4]. In addition, vinorelbine has to be administrated carefully as the clearance rate decreases in patients with suppression of liver function [5]. We report on the successful treatment of a jaundiced patient with excessive liver metastases of breast cancer and progressive hepatic failure using a combined chemotherapy with mitomycin, folinate, and 5-fluorouracil (Mi/Fo/FU).

\section{Case Report}

A 45-year-old woman with a history of stage II breast cancer presented in poor general condition, with loss of appetite, severe fatigue, massive newly developed ascites, distended abdomen, and extensive jaundice. Symptoms developed rapidly over a period of only 3-4 weeks. Breast cancer had been diagnosed 2 years before and had been clinically classified as cT2 cN1 G3 M0. Histologically, an invasive ductal carcinoma could be immunohistochemically confirmed with negative hormonal receptor status (estrogen receptor score 0 , progesterone receptor score 0 ) and absence of any HER2/neu expression (HER2/neu score 0 ). The patient underwent primary systemic therapy with 4 cycles of pemetrexed/doxorubicin and 4 cycles of docetaxel with suboptimal response, followed by breast conserving surgery and radiation therapy of the breast and regional lymph nodes. The tumor stage according to the final histopathology was ypT1c ypN1a (1/11) G3 L0 R0 M0.

During the current admission, clinical examination revealed an extensively jaundiced patient with findings as described above, resulting in an ECOG status 3. Abnormal blood chemistry reports included elevated bilirubin of $7.9 \mathrm{mg} / \mathrm{dl}$ and excessively elevated liver enzymes (aspartate

aminotransferase (ASAT) $271 \mathrm{U} / 1$, alanine transaminase (ALAT) $101 \mathrm{U} / \mathrm{l}$ ). Abdominal ultrasound demonstrated multiple disseminated hepatic metastases in both liver lobes. An endoscopic cholangiopancreaticography was performed but did not show any biliary dilatation. The clinical performance status decreased rapidly, and the patient became somnolent. Ascites was released continuously. In addition, thrombocytopenia complicated the situation, and multiple thrombocyte transfusions had to be administered before starting any further treatment. A combined palliative chemotherapy regimen consisting of $\mathrm{Mi} / \mathrm{Fo} / \mathrm{FU}$ was started at $50 \%$ of the standard dose for the first 2 cycles. As the performance status of the patient improved, we escalated the dose up to $100 \%$ for the following 3 cycles. Chemotherapy was administered in a 3 -week interval. The standard-dose regimen consisted of mitomycin $\mathrm{C}\left(8 \mathrm{mg} / \mathrm{m}^{2}\right.$ intravenously (i.v.)), folinic acid (500 $\mathrm{mg}$ in total), and 5-fluorouracil $\left(750 \mathrm{mg} / \mathrm{m}^{2} \mathrm{i} . \mathrm{v}\right.$.) on day 1 plus folinic acid $\left(500 \mathrm{mg}\right.$ in total) and 5 -fluorouracil $\left(750 \mathrm{mg} / \mathrm{m}^{2}\right.$ i.v. $)$ on day 2. After the first cycle of chemotherapy, bilirubin initially increased up to $21 \mathrm{mg} / \mathrm{dl}$ and then continuously decreased. Six weeks later, the bilirubin serum levels had normalized (fig. 1). Similar findings were observed for the hepatic enzymes (fig. 2). Furthermore, CA 15-3 serum levels decreased continuously (fig. 3). In parallel, the ascites volume decreased after the second cycle of chemotherapy, and the clinical performance of the patient improved. Four weeks after starting Mi/Fo/FU, the patient showed an ECOG 1-2 and was able to participate in regular family life again. All following cycles of chemotherapy were administered in an outpatient setting without any therapy-limiting toxicities and with no need for dose reduction. Moreover, dose escalation of up to $100 \%$ was made possible by the rapid improvement of the patient's condition after the second cycle of Mi/Fo/FU. During therapy, grade 1 thrombocytopenia was observed, furthermore a mild nausea corresponding to a grade 1 nonhematologic toxicity. No grade 3 or 4 toxicity was observed.

Besides the impressive clinical treatment response, the serum levels of CA 15-3 fell rapidly during therapy and finally normalized. The progression-free interval was 5 months. After that, CA 15-3 rose again and the patient showed signs of bone marrow depletion consistent with a suspected progressive bone marrow carcinosis so that treatment had to be discontinued.

Fig. 1. Course of serum levels of aspartate aminotransferase (AST) and alanine transaminase (ALT) during chemotherapy.

Fig. 2. Course of bilirubin serum levels during chemotherapy.

Fig. 3. Course of CA 15-3 serum levels during chemotherapy.
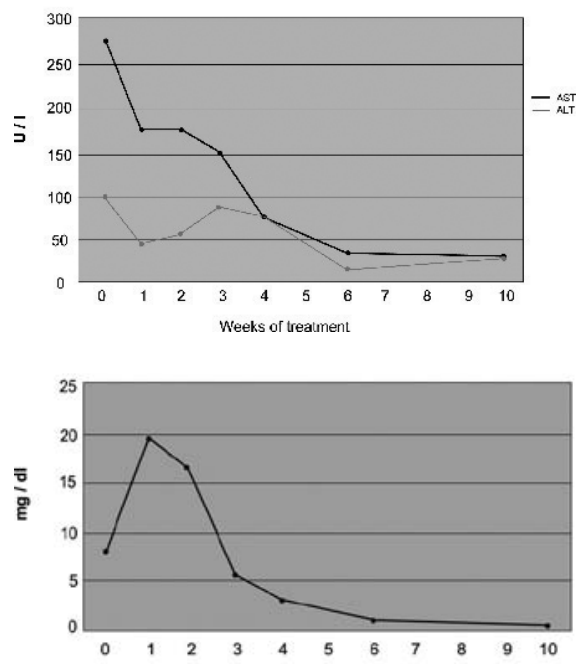

Weeks of traatment

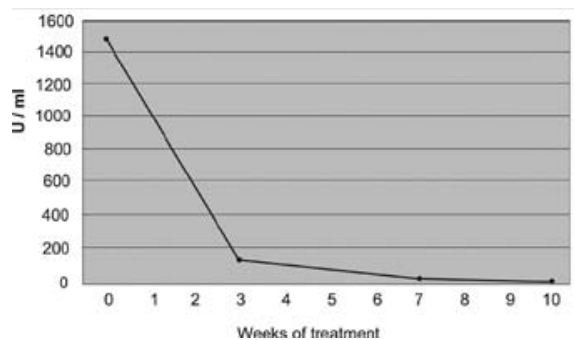


Table1. Palliative chemotherapy regimens after anthracycline and taxane failure according to the current AGO guidelines; table modified and adjusted with respect to the currently documented experience on patients with reduced liver function

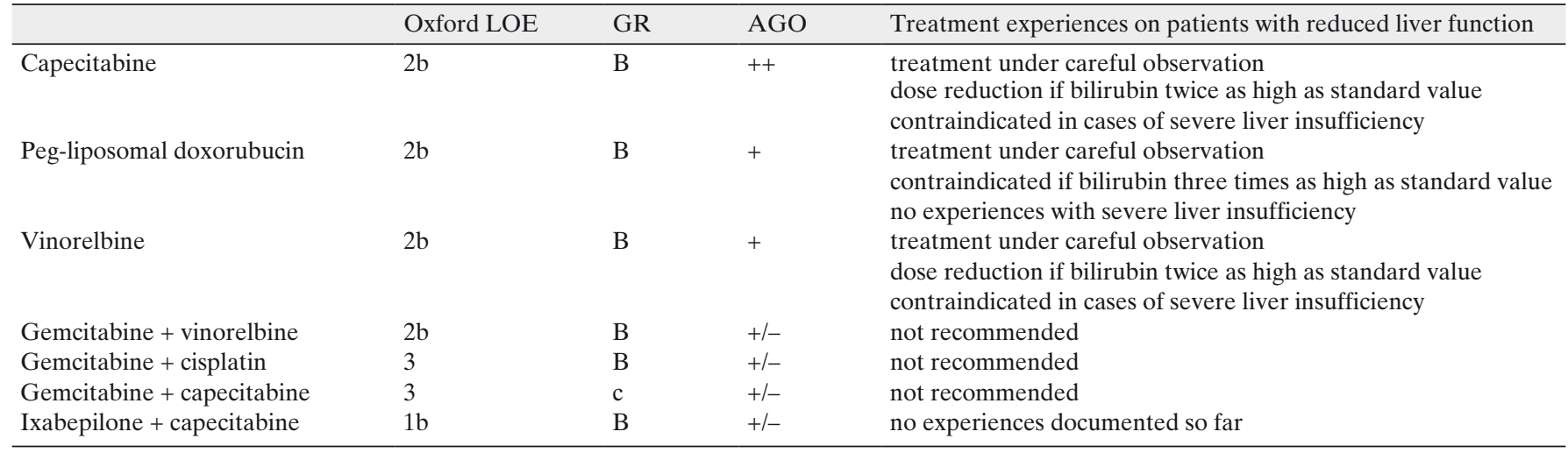

LOE = Level of evidence; GR = grade of recommendation; AGO = Arbeitsgemeinschaft für Gynäkologische Onkologie.

\section{Discussion}

Systemic treatment of MBC with liver involvement and jaundice often is considered futile due to poor prognosis, limited therapeutic options, and the risk of unpredictable toxicity. Anthracycline- and taxane-containing regimens, established as standard chemotherapy treatment options for the first-line treatment of endocrine-resistant $\mathrm{MBC}$, are metabolized and excreted by the liver and may cause severe side effects in patients with impaired liver function [6]. Doxorubicin is considered to be contraindicated for patients with elevated bilirubin serum levels, and the doses of several other drugs have to be adjusted. On the other hand, liver metastases are considered to be less responsive to chemotherapy [4]. So far, there is no consensus defined for the systemic treatment of MBC after failure of a first-line therapy, although there is a variety of drugs that have been well evaluated such as capecitabine (table 1). For patients with a poor clinical performance status, the administration of chemotherapy has to be discussed carefully, as the benefit can be only marginal. Patients with jaundice are at higher risk for toxicity, and treatment options therefore have to be analyzed in detail. A combination chemotherapy consisting of $\mathrm{Mi} / \mathrm{Fo} / \mathrm{FU}$ has been shown to be active and safe in the treatment of patients with advanced liver metastases secondary to breast cancer and hepatic dysfunction [7]. Eichbaum et al. [8] reported a retrospective analysis of 76 breast cancer patients with predominant liver metastases with a clinical benefit for the combined chemotherapy with $\mathrm{Mi} / \mathrm{Fo} / \mathrm{FU}$ at a rate of $58 \%$; similar data are shown on 44 patients with a clinical benefit of $64 \%$ [9]. A benefit of up to $50 \%$ and a median overall survival of 12.0 months under the treatment with Mi/ Fo/FU in patients with impaired hepatic function were reported by Loibl et al. [7]. In summary, Mi/Fo/FU seems to be a well tolerated regimen. In our case, the $\mathrm{Mi} / \mathrm{Fo} / \mathrm{FU}$ regimen was used as a salvage treatment for a breast cancer patient with hepatic failure. The aims of therapy in the palliative setting, such as relief of symptoms, improvement of quality of life, possible prolongation of survival, and therapy administration in an outpatient setting, could successfully be achieved.

In summary, a combined chemotherapy regimen with $\mathrm{Mi} / \mathrm{Fo} /$ FU appears to be a reasonable and well tolerated alternative salvage treatment option for patients with liver metastases from breast cancer. The regimen is active and feasible also in patients showing clinical signs of reduced or impaired hepatic function. This strategy may offer an important option for MBC patients with reduced performance status and limited treatment options due to hepatic impairment as a result of liver metastases.

\section{Conflict of Interest}

No conflict of interest for any of the authors can be stated.

\section{References}

1 Jaffe BM, Donegan WL, Watson F, Spratt J: Factors influencing survival in patients with untreated hepatic metastasis. Surg Gynecol Obstet 1968;127:1-11.

-2 Zinser JW, Hortobagyi GN, Buzdar AU, Smith TL, Fraschini G: Clinical course of breast cancer patients with liver metastases. J. Clin Oncol 1987;5:773-782.

$\checkmark 3$ Eichbaum HM, Kaltwasser M, Bruckner T, de Rossi TM, Schneeweiss A, Sohn C: Prognostic factors for patients with liver metastases from breast cancer Breast Cancer Res Treat 2006;96:53-62.

4 Robinson K, Lambiase L, Li J, Monteiro C, Schiff M: Fatal cholestatic liver failure associated with gemcitabine therapy. Dig Dis Scie 2003;48:1804-1808.
Robieux I, Sorio R, Borsatti E, Cannizzaro R, Vitali V, Aita P: Pharmacokinetics of vinorelbine in patients with liver metastases. Clin Pharmacol Ther 1996;59:32-40.

6 Feenstra J, Vermeer RJ, Stricker BH: Fatal hepatic coma attributed to paclitaxel. J Nat Can Inst 1997; 89:582-583.

7 Loibl S, von Minckwitz G, Schwedler K, Schmidt KA, Höper D, Kaufmann M Costa SD: Mitomycin C, 5-fluorouracil and folinic acid (Mi-Fo-Fu) as salvage chemotherapy in breast cancer patients with liver metastases and impaired hepatic function: a phase II study. Anti Can Drugs 2004;15:719724.
8 Eichbaum MH, Gast AS, Schneeweiss A, Bruckner T, Sohn C: Activity and tolerability of a combined palliative chemotherapy with mitomycin $\mathrm{C}$, folinate, and 5-fluorouracil in patients with advanced breast cancer after intensive pretreatment. A J Clin Oncol 2007;30:139-145.

9 Eichbaum MH, Gast AS, Bruckner T, Schneeweiss A, Sohn C: Combined chemotherapy with mitomycin $\mathrm{C}$, folinic acid and 5-fluorouracil (MiFoFU) as salvage treatment for patients with liver metastases from breast cancer - a retrospective analysis. Breast Care 2008;3:262-267. 